\title{
Pregnancy outcomes in Korean women with ankylosing spondylitis
}

\author{
Eun Hye Park ${ }^{1,{ }^{*}}$, Jung Sun Lee ${ }^{2, *}$, Ye-Jee Kim³ ${ }^{3}$, Seung Mi Lee ${ }^{4}$, Jong Kwan Jun ${ }^{4}$, Eun Bong Lee ${ }^{1}$, and \\ Yong-Gil Kim ${ }^{2}$
}

\begin{abstract}
${ }^{1}$ Division of Rheumatology, Department of Internal Medicine, Seoul National University College of Medicine, Seoul; ${ }^{2}$ Division of Rheumatology, Department of Internal Medicine, Asan Medical Center, University of Ulsan College of Medicine, Seoul; ${ }^{3}$ Department of Clinical Epidemiology and Biostatistics, Asan Medical Center, Seoul; ${ }^{4}$ Department of Obstetrics and Gynecology, Seoul National University College of Medicine, Seoul, Korea
\end{abstract}

\section{Received: April 26, 2019 \\ Revised: July 6, 2019 \\ Accepted: July 27, 2019}

\section{Correspondence to \\ Yong-Gil Kim, M.D.}

Division of Rheumatology,

Department of Internal

Medicine, Asan Medical Center,

University of Ulsan College of

Medicine, 88 Olympic-ro 43-gil,

Songpa-gu, Seoul 05505, Korea

Tel: +82-2-3010-3279

Fax: +82-2-3010-6969

E-mail: bestmd200o@amc.seoul.kr https://orcid.org/0000-0002-

8029-7355

*These authors contributed equally to this work.
Background/Aims: Because ankylosing spondylitis (AS) mainly affects sacroiliac joints, special attention should be given to normal labour and pregnancy outcomes. Here, we investigate pregnancy outcomes in Korean women with AS.

Methods: Based on data from the Korean Health Insurance Review and Assessment Service claims database since July 2007 , maternal complications were compared between women with AS and 1:10 matched general population by maternal age and year of delivery. Additionally, the 27 deliveries from 21 patients with AS who were seen at a tertiary hospital were retrospectively evaluated using 1:4 matched control group by maternal and gestational age.

Results: In the population-based cohort, there were 1,293 deliveries in 996 patients with AS. Higher maternal age and more comorbidities were reported than in the general population. However, compared to age and delivery-year matched population, only the rate of Caesarean section (CS) was higher in women with AS (odds ratio, 1.52; 95\% confidence interval, 1.36 to 1.70). Incidence of other maternal complications was comparable between women with AS and control subjects. In the hospital-based cohort, the CS rate was higher in women with AS (44.4\% vs. $20.4 \%, p=0.002$ ). Causes of CS was not different in both groups, including previous uterine surgery. There were no significant differences in foetal outcomes, including growth restriction, foetal malformations and Apgar score.

Conclusions: CS deliveries were performed more often in women with AS. However, other maternal complications and offspring complications were similar between women with AS and healthy control subjects.

Keywords: Spondylitis, ankylosing; Pregnancy; Caesarean section

\section{INTRODUCTION}

Ankylosing spondylitis (AS) is a chronic, systemic, inflammatory disease that primarily affects the sacroiliac joints and spine. Similar to the involvement of the axial skeleton and peripheral joints, entheses and extra-skeletal organs may also be affected [1]. Estimates of the prevalence of AS range from 0.7 to 49 per 10,000 people, depending on regional, genetic, and environmental factors. The prevalence tends to be higher in populations with a higher prevalence of HLA-B27 positivity [2]. AS typically develops in young adults, with peak onset observed between 20 and 30 years of age. Although the early literature suggested that AS was a male-predominant 
disease [3], recent epidemiological studies demonstrated a male-to-female ratio of approximately 2 to $3: 1$ [4]. Although AS affects men more commonly than women, the disease occurs in women of reproductive age. In addition, because AS is a disease involving the sacroiliac joints, and ankyloses of the joint occurs as the disease progresses, special attention should be given to normal labour and pregnancy outcomes in female patients with AS.

Unlike other rheumatic diseases such as systemic lupus erythematosus and rheumatoid arthritis, very little is known and has been published about the effect of AS on pregnancy outcomes. Most previous studies showed that pregnancy outcomes were not adversely affected by AS $[5,6]$. In contrast, a recent Swedish nationwide population-based case-control study [7] reported a higher prevalence of adverse birth outcomes, such as Caesarean section (CS), preterm birth and small-for-gestational-age (SGA), in women with AS. To the best of our knowledge, there are few studies regarding pregnancy outcomes and AS in Asian women who have relatively small pelvic cavities and more potential complications during pregnancy and delivery compared to other women [8-10].

Korea implements mandatory National Health Insurance (NHI) that covers about $98 \%$ of the population. Pregnancy outcomes in almost every woman with AS who visited a healthcare clinic in Korea during the study period were accessible through the Health Insurance Review and Assessment Service (HIRA) nationwide claims database, which is covered by the NHI programme. However, the HIRA database does not provide the indications for CS or foetal outcomes, such as Apgar score and birth weight. To remedy these shortcomings, a hospital-based retrospective cohort study was also used. This enabled a more comprehensive and reliable analysis of pregnancy outcomes in patients with AS. In this study, pregnancy outcomes in patients with AS are presented based on a Korean population cohort and more detailed maternal and foetal outcomes using a large hospital-based cohort.

\section{METHODS}

\section{Data sources}

This population-based cohort study used the HIRA da-

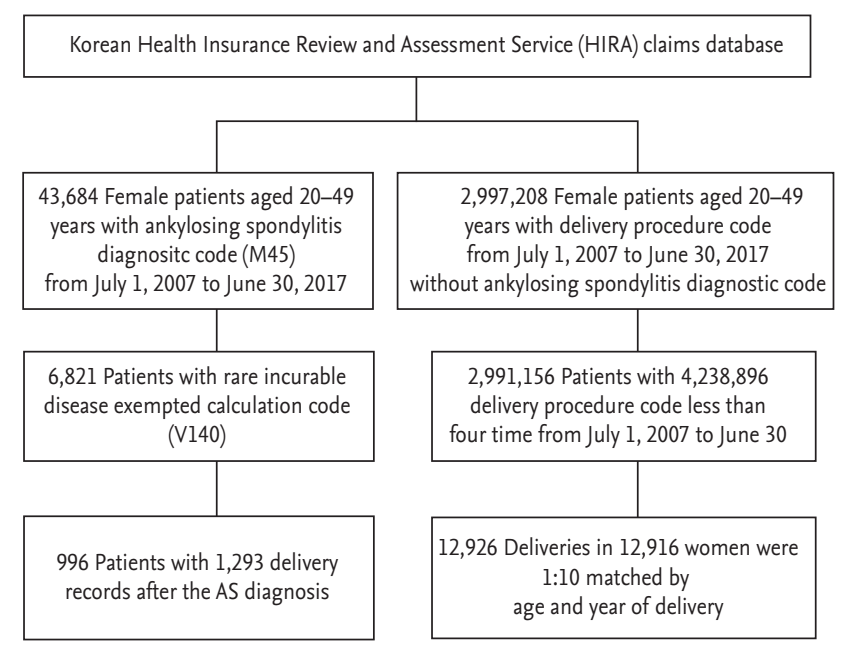

Figure 1. Selection of study participants from the Health Insurance Review and Assessment Service database. AS, ankylosing spondylitis.

tabase, which included all health-related information for approximately 50 million people in the South Korean population covered by the NHI programme. It contained information on patient demographics, diagnosis (using International Classification of Disease and Related Health Problems, 1oth revision, [ICD-10]), medical procedures, prescriptions and rare intractable diseases (RIDs) [11]. Prescription data included brand and generic drug names according to the HIRA drug formulary code, prescription date, days of supply and route of administration. Since 2006, the NHI operated a registration system for 133 RIDs, including AS. In the Korean RID system, diagnosis was made based on uniform diagnostic criteria distributed by the NHI and carefully reviewed by the corresponding healthcare institution and the NHI before registration. The hospital-based cohort study utilized medical records from the Seoul National University Hospital which contains information on demographic and clinical data, such as age, body mass index (BMI), educational level, smoking status, obstetric history, comorbidities, laboratory analysis and medical treatment, and maternal and foetal pregnancy outcomes.

\section{Study subjects}

As shown in Fig. 1, the population-based cohort consisted of patients with AS and control subjects. From 2007 to 2017,20 - to 49 -year-old female patients with AS were identified. Patients diagnosed with AS (ICD-10, M45) and with RID registration code for AS (V140) were included. 
Table 1. Clinical characteristics of women with AS and controls: Korean HIRA claims database

\begin{tabular}{|c|c|c|c|c|c|c|c|}
\hline \multirow{2}{*}{ Characteristic } & \multicolumn{4}{|c|}{ Before matching } & \multicolumn{3}{|c|}{ After matching $^{\mathrm{a}}(1: 10)$} \\
\hline & With AS & Without AS & $p$ value $^{\mathrm{b}}$ & $d^{\mathrm{c}}$ & With AS & Without AS & $d^{\mathrm{c}}$ \\
\hline No. of deliveries & $1,293(100)$ & $4,238,896(100)$ & & & $1,293(100)$ & $12,926(100)$ & \\
\hline Year of delivery & & & $<0.001$ & 0.498 & & & 0.000 \\
\hline 2007-2010 & $204(15.8)$ & $1,123,099(36.4)$ & & & $204(15.8)$ & $2,040(15.8)$ & \\
\hline $2011-2013$ & $456(35 \cdot 3)$ & $1,310,325(31)$ & & & $456(35 \cdot 3)$ & $4,560(35 \cdot 3)$ & \\
\hline 2014-2017 & $633(48.9)$ & $455,453(32.8)$ & & & $633(48.9)$ & $6,326(48.9)$ & \\
\hline Maternal age, yr & $32 \pm 3 \cdot 4$ & $31.1 \pm 4.1$ & $<0.001$ & 0.357 & $32 \pm 3 \cdot 4$ & $32 \pm 3 \cdot 4$ & 0.012 \\
\hline $20-24$ & $12(0.9)$ & $236,460(5.6)$ & & & $12(0.9)$ & $120(0.9)$ & \\
\hline $25-29$ & $260(20.1)$ & $1,208,897(28.5)$ & & & $260(20.1)$ & $2,600(20.1)$ & \\
\hline $30-34$ & $708(54.8)$ & $1,988,052(46.9)$ & & & $708(54.8)$ & $7,080(54.8)$ & \\
\hline $35-39$ & $287(22.2)$ & $710,732(16.8)$ & & & $287(22.2)$ & $2,870(22.2)$ & \\
\hline $40-44$ & $25(1.9)$ & $92,288(2.2)$ & & & $25(1.9)$ & $250(1.9)$ & \\
\hline $45-49$ & $1(0.1)$ & 2,467 (0.1) & & & $1(0.1)$ & $6(0.1)$ & \\
\hline Parity & & & $<0.001$ & 0.108 & & & 0.169 \\
\hline Nulliparous & $749(57 \cdot 9)$ & $2,227,398(52.6)$ & & & $749(57.9)$ & $6,403(49 \cdot 5)$ & \\
\hline Multiparous & $544(42.1)$ & $2,011,498(47 \cdot 5)$ & & & $544(42.1)$ & $6,523(50.5)$ & \\
\hline \multicolumn{8}{|l|}{ Comorbidity $^{\mathrm{d}}$} \\
\hline Hypertension & $25(1.93)$ & $53,890(1.3)$ & 0.034 & 0.053 & $25(1.93)$ & $173(1.3)$ & 0.047 \\
\hline Diabetes mellitus & $33(2.6)$ & $96,963(2.3)$ & 0.524 & 0.017 & $33(2.6)$ & $347(2.7)$ & 0.008 \\
\hline Uveitis & $204(15.8)$ & $5,228(0.1)$ & $<0.001$ & 0.605 & $204(15.8)$ & $22(0.2)$ & 0.602 \\
\hline IBD & $138(10.7)$ & $1,845(0.0)$ & $<0.001$ & 0.486 & $138(10.7)$ & $2(0.0)$ & 0.488 \\
\hline Psoriasis & $19(1.5)$ & $15,825(0.4)$ & $<0.001$ & 0.115 & $19(1.5)$ & $48(0.4)$ & 0.115 \\
\hline \multicolumn{8}{|l|}{ Drug exposure ${ }^{\mathrm{d}}$} \\
\hline NSAIDs & $506(39.1)$ & $304,590(7.2)$ & $<0.001$ & 0.818 & $506(39.1)$ & $876(6.8)$ & 0.834 \\
\hline Corticosteroid & $270(20.9)$ & $17,122(0.4)$ & $<0.001$ & 0.704 & $270(20.9)$ & $50(0.4)$ & 0.705 \\
\hline DMARDs & $223(17 \cdot 3)$ & 1,368 (0.0) & $<0.001$ & 0.644 & $223(17 \cdot 3)$ & $6(0.1)$ & 0.643 \\
\hline TNF inhibitors & $136(10.5)$ & $393(0.0)$ & $<0.001$ & 0.484 & $136(10.5)$ & $1(0.0)$ & 0.484 \\
\hline
\end{tabular}

Values are presented as number (\%) or mean $\pm \mathrm{SD}$.

AS, ankylosing spondylitis; HIRA, Health Insurance Review and Assessment Service; IBD, inflammatory bowel disease; NSAID, nonsteroidal anti-inflammatory drug; DMARD, disease-modifying anti-rheumatic drug; TNF, tumour necrosis factor.

${ }^{a}$ Matched by maternal age and year of delivery.

${ }^{\mathrm{b}} \mathrm{p}$ value estimated by chi-square test.

${ }^{\mathrm{c}}$ Standardised difference: standardised difference less than 0.1 indicated a negligible difference.

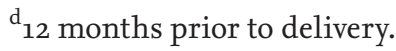

All deliveries after the AS diagnosis contained information on parity, multiple birth and delivery method. The comparison cohort consisted of 4,238,896 deliveries in all 20- to 49-year-old females without AS during the study period. ICD-10 codes used in the population-based cohort study are summarised in Supplementary Table 1. Common comorbidities (hypertension, diabetes mel- litus, uveitis, inflammatory bowel disease, and psoriasis) and use of medications (nonsteroidal anti-inflammatory drugs [NSAIDs], oral corticosteroids for at least 14 days, disease-modifying anti-rheumatic drugs, and anti-tumour necrosis factor inhibitors) were compared between patients with AS and control subjects. This study protocol was approved by the Institutional Review 
Table 2. Pregnancy outcomes in women with AS and controls: Korean HIRA claims database

\begin{tabular}{|c|c|c|c|c|c|c|}
\hline Outcome & $\begin{array}{l}\text { With AS } \\
(\mathrm{n}=1,293)\end{array}$ & $\begin{array}{l}\text { Without AS } \\
(n=12,926)\end{array}$ & OR & $95 \%$ CI & Adjusted OR & $95 \% \mathrm{CI}$ \\
\hline No complication (ref) & $602(46.6)$ & $7,421(57.4)$ & 1.00 & & 1.00 & \\
\hline Overall complication & $691(53.4)$ & $5,505(42.5)$ & 1.55 & $1.38-1.73$ & $1.52^{\mathrm{a}}$ & $1.36-1.70$ \\
\hline Caesarean section & $657(50.8)$ & $5,098(39 \cdot 3)$ & 1.58 & $1.41-1.77$ & $1.56^{\mathrm{a}}$ & $1.39-1.74$ \\
\hline Preeclampsia & $17(1.3)$ & $101(0.8)$ & 1.70 & $1.01-2.86$ & $1.56^{\mathrm{b}}$ & $0.91-2.67$ \\
\hline Preterm delivery & $18(1.4)$ & $174(1.3)$ & 1.06 & $0.65-1.71$ & $1.05^{\mathrm{c}}$ & $0.54-1.68$ \\
\hline Placental abruption & $0(0.0)$ & $23(0.2)$ & $\mathrm{NE}$ & & & \\
\hline Other obstetric trauma & $16(1.2)$ & $239(1.8)$ & 0.66 & $0.40-1.10$ & $0.64^{\mathrm{d}}$ & $0.39-1.07$ \\
\hline $\begin{array}{l}\text { Maternal distress during } \\
\text { labour and delivery }\end{array}$ & o & $10(0.2)$ & $\mathrm{NE}$ & & & \\
\hline Twin pregnancy & $10(0.8)$ & $82(0.6)$ & 1.21 & $0.63-2.34$ & $1.41^{\mathrm{d}}$ & $0.75^{-2.07}$ \\
\hline
\end{tabular}

Values are presented as number (\%).

AS, ankylosing spondylitis; HIRA, Health Insurance Review and Assessment Service; OR, odds ratio; CI, confidence interval; NE, not estimated.

${ }^{a}$ Adjusted for parity, twin pregnancy, presence of hypertension and diabetes mellitus.

bAdjusted for presence of hypertension.

${ }^{\mathrm{c}}$ Adjusted for twin pregnancy, presence of hypertension and diabetes mellitus.

${ }^{\mathrm{d}}$ Adjusted for parity. Odds ratio of maternal complications compared between two groups using a generalized linear model with binomial distribution to account for the matched nature of the data.

Board of the Asan Medical Center (IRB No. 2017-0431). Informed consent was waived by the IRB because the existing database provided data in a de-identified format.

Supplementary Fig. 1 summarizes our study selection process in the hospital-based cohort. In the hospital-based cohort, medical records were reviewed for all pregnant women with AS who were managed at the Department of Obstetrics and Gynecology at Seoul National University Hospital between February 1994 and June 2016. All patients met the 1984 Modified New York criteria for AS [12]. Data of 27 pregnancies of 21 women with AS were reviewed, and each pregnancy was matched on a 1:4 ratio based on maternal and gestational age with the pregnancies of the control group women without any autoimmune diseases. This study was approved by the Institutional Review Board of Seoul National University Hospital (IRB No. H-1607-115-777).

\section{Pregnancy outcomes}

In the population-based cohort, pregnancy complication was defined by the proportion of deliveries with CS, preeclampsia, preterm delivery, other obstetric trauma, and maternal distress. Information regarding complica- tions was retrieved from the diagnostic codes (Supplementary Table 1).

In the hospital-based cohort, maternal and foetal outcomes were analysed. Maternal outcome was defined by rate of CS, preeclampsia, preterm delivery, maternal death, transfusion, gestation weeks, and mean duration of hospital days. Foetal outcome was reviewed by SGA, low birth weight (LBW), neonatal weight, number of foetuses, in vitro fertilisation, foetal growth restriction (FGR), any foetal congenital malformations, foetal loss, Apgar scores, and sex of the child. Preeclampsia was defined as hypertension (blood pressure $\geq 140 / 90 \mathrm{mmHg}$ ) combined with proteinuria (>300 mg/day) arising de novo after the 2oth week of gestation [13]. Preterm delivery was defined as a live birth at less than 37 weeks of gestation. LBW was defined as a birth weight of $<2,500 \mathrm{~g}$, and FGR was growth index below the 1oth percentile for gestational age [14]. SGA was defined as a birth weight below the 1oth percentile for the gestational age, based on the Korean reference curve of estimated fetal growth [15]. Low Apgar score was lower than 4 at 1 minute and lower than 7 at 5 minutes [16]. Our ascertainment of foetal congenital malformations was based on presence at birth. 
Table 3. Maternal outcomes in women with AS and controls: hospital-based cohort

\begin{tabular}{lccc}
\hline Outcome & With AS $(\mathrm{n}=27)$ & Without AS $(\mathrm{n}=108)$ & $p$ value \\
\hline Caesarean section & $12(44.4)$ & $22(20.4)$ & 0.002 \\
\multicolumn{1}{c}{ Elective } & $9(33.3)$ & $16(14.8)$ & 0.010 \\
\multicolumn{1}{c}{ Emergency } & $3(11.1)$ & $6(5.6)$ & 0.357 \\
CS among trial of labor & $1 / 16(6.3)$ & $4 / 90(4.4)$ & 0.566 \\
Preeclampsia & 0 & $4(3.7)$ & $0.583^{\mathrm{b}}$ \\
Preterm delivery & $3(11.1)$ & $6(5.6)$ & 0.275 \\
Maternal death & 0 & 0 & - \\
Transfusion & $1(3.7)$ & $2(1.9)$ & 0.577 \\
Gestation, wk & $38.8 \pm 1.5$ & $39.0 \pm 1.8$ & 0.730 \\
Hospital stay, day & $4.1 \pm 2.9)$ & $5.1 \pm 7.9$ & 0.283 \\
\hline
\end{tabular}

Values are presented as number (\%) or mean $\pm \mathrm{SD}$.

AS, ankylosing spondylitis; CS, Caesarean section.

${ }^{a} p$ value calculated from regression models estimated using generalised estimating equations (GEEs) to account for the matched nature of the data.

${ }^{\mathrm{b}} \mathrm{p}$ value calculated from Fisher exact test, because of zero events in either group in which GEE models do not converge.

\section{Statistical analysis}

In the population-based cohort, all statistical analyses were performed using SAS Enterprise Guide software version 6.1 (SAS Institute Inc., Cary, NC, USA). The distribution of baseline characteristics was compared by the standardised difference between patients with AS and control subjects. A total of 1,293 deliveries of patients with AS was matched with the comparison cohort in a 1:10 ratio by year of delivery and maternal age. Risk of maternal complications was compared between two groups using a generalised linear model with binomial distribution to account for the matched nature of the data. Multivariate analysis was performed to determine the risk of each pregnancy outcome between two groups after adjusting for potential confounders. Among the covariates (parity, twin pregnancy, or presence of comorbidities) which the $p$ value was < 0.1 in the univariate analysis was included, and model selection with quasi-likelihood under the independence model criterion method. A $p<0.05$ was considered statistically significant.

In the hospital-based cohort, all statistical analyses were performed using the SPSS version 23 (IBM Co., Armonk, NY, USA). Quantitative variables were reported as mean \pm standard deviation. Absolute and relative frequencies were used for categorical variables. Each pregnancy was considered as a separate observation, and outcomes between the groups were compared by estimated regression models using generalised estimating equations to account for the matched nature of the data. Each twin pregnancy was considered as a single observation, but variables including neonatal weight, sex, and Apgar scores were analysed by the neonates. Statistical significance was set at $p<0.05$.

In both population- and hospital-based cohorts, sensitivity analyses were performed by limiting pregnancy to first delivery in each mother, as a previous delivery with CS mostly resulted in a subsequent CS delivery.

\section{RESULTS}

\section{Baseline clinical characteristics}

The Korean cohort consisted of 6,821 fertile women with AS, including 996 women who delivered from 2007 to 2017. A total of 1,293 deliveries in 996 women with AS were compared with 4,238,896 deliveries in 2,997,208 control subjects. The mean disease duration of AS before pregnancy was $4.18 \pm 2.38$ years. Deliveries in patients with AS showed older age, higher rate of nulliparous and comorbidity in uveitis, inflammatory bowel disease, and psoriasis compared with deliveries without 
Table 4. Foetal outcomes in women with AS and controls: hospital-based cohort

\begin{tabular}{|c|c|c|c|}
\hline Characteristic & With $\mathrm{AS}^{\mathrm{a}}(\mathrm{n}=27)$ & Without AS $(\mathrm{n}=108)$ & $p$ value $^{b}$ \\
\hline Low birth weight & $6(22.2)$ & $9(8.3)$ & 0.024 \\
\hline Small-for-gestational-age & $3(11.1)$ & $10(9 \cdot 3)$ & 0.723 \\
\hline Neonatal weight, $\mathrm{g}^{\mathrm{c}}$ & $2,960.3 \pm 523.8$ & $3,065 \cdot 3 \pm 509 \cdot 4$ & 0.370 \\
\hline Twin pregnancy & $5(18.5)$ & $8(7 \cdot 4)$ & 0.016 \\
\hline In vitro fertilisation & $4(14.8)$ & $11(10.2)$ & 0.500 \\
\hline Fetal growth restriction & $2(7 \cdot 4)$ & $5(4 \cdot 6)$ & 0.597 \\
\hline Congenital malformation & $1(3 \cdot 7)$ & $2(1.9)$ & 0.491 \\
\hline Fetal loss & 0 & 0 & - \\
\hline 1 min Apgar score $<4^{c}$ & $1(3.1)$ & $7(6.1)$ & $>0.999$ \\
\hline 5 min Apgar score $<7^{c}$ & $1(3.1)$ & $4(3 \cdot 5)$ & $>0.999$ \\
\hline Sex of child, female ${ }^{c}$ & $17(53.1)$ & $63(54.8)$ & 0.883 \\
\hline
\end{tabular}

Values are presented as number (\%) or mean \pm SD.

AS, ankylosing spondylitis.

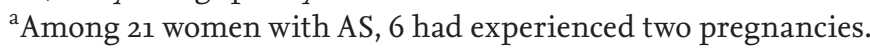

${ }^{b} p$ value calculated from regression models estimated using generalised estimating equations (GEEs) to account for the matched nature of the data.

${ }^{\mathrm{c}}$ Analysed by neonates and information of twins, pregnancies with $\mathrm{AS}(\mathrm{n}=32)$ and pregnancies without $\mathrm{AS}(\mathrm{n}=116)$.

AS. In addition, the rate of exposure to drugs was higher in deliveries with AS than in deliveries without AS (Table 1).

In the hospital-based cohort, 135 pregnancies were included in the analysis. Of these, 27 deliveries occurred in 21 women with AS with 108 deliveries occurred in the control group. The mean age at pregnancy was $32.3 \pm 3.2$ years, and the mean duration of AS before pregnancy was 4.1 \pm 2.7 years (Supplementary Table 2). The proportion of nulliparity was $59.3 \%$ in women with AS and $62 \%$ in control subjects $(p=0.853)$. There were no current smokers in either group and pre-pregnancy BMI, education level, parity, previous delivery method, and comorbidities were similar between the two groups. Of the 21 pregnancies in women with AS whose rheumatology medical records were available, 18 (85.7\%) were HLA-B27 positive, and $100 \%, 28.6 \%, 47.6 \%$, and $28.6 \%$ had used NSAIDs, corticosteroids, sulfasalazine, and biologic agents before conception, respectively.

\section{Pregnancy outcomes}

In the population-based cohort, the rate of CS was higher in women with AS than those without AS (50.8\% vs. $39.3 \%$ ), and the risk of CS was higher in AS (adjusted odds ratio [OR], 1.56; 95\% confidence interval [CI], 1.39 to
1.74) (Table 2). Thus, the risk of overall pregnancy complication was higher in women with AS than those without AS (adjusted OR, 1.52; 95\% CI, 1.36 to 1.70). However, other pregnancy complications were similar between the two groups. Most of the women with AS had a single complication; only 23 (1.78\%) had dual or triple complications simultaneously.

In the hospital-based cohort, CS was more frequently performed in women with AS than in control subjects (12/27 [44.4\%] vs. $22 / 108$ [20.4\%], p = 0.002) (Table 3). In addition, the rate of elective CS was higher in women with AS than in those without AS. After excluding the cases of elective CS, 16 pregnancies with AS were tried for the vaginal delivery. Among those trials of labor (TOL), one delivery (6.3\%) resulted in CS, which was comparable to the control group (four cases out of 90 TOL [4.4\%], $p=$ 0.566). Furthermore, preeclampsia and preterm delivery were similar in the two groups, and there was no maternal death in either group.

Women with AS had a higher frequency of LBW infants than control subjects $(22.2 \%$ vs. $8.3 \%, p=0.024)$ (Table 4). In addition, the proportion of twin pregnancy was higher in women with AS than in control subjects (18.5\% vs. $7.4 \%, p=0.016$ ), despite comparable rates of in vitro fertilisation in both groups ( $14.8 \%$ vs. $10.2 \%, p=$ 
Table 5. Indications of Caesarean section: hospital-based cohort

\begin{tabular}{lccr}
\hline Caesarean risk factor & With AS $(\mathrm{n}=12)$ & Without AS $(\mathrm{n}=22)$ & $p$ value \\
\hline Previous caesarean section & $4(33.3)$ & $10(45.5)$ & 0.719 \\
Breech delivery & $3(25.0)$ & $3(13.6)$ & 0.641 \\
Failure to progress & $1(8.3)$ & $2(9.1)$ & 0.999 \\
Induction failure & 0 & $2(9.1)$ & 0.529 \\
Previous uterine (obstetric) surgery & $1(8.3)$ & $2(9.1)$ & 0.983 \\
Placenta previa & $2(16.7)$ & 0 & $0.118^{\mathrm{b}}$ \\
Foetal distress & $1(8.3)$ & $3(13.6)$ & $>0.999$ \\
Maternal age $(\geq 40 \mathrm{yr})$ & $1(8.3)$ & $1(4.5)$ & $>0.999$ \\
Maternal obesity $\left(\mathrm{BMI} \geq 30 \mathrm{~kg} / \mathrm{m}^{2}\right)$ & 0 & $2(9.1)$ & $0.529^{\mathrm{b}}$ \\
\hline
\end{tabular}

Values are presented as number (\%).

AS, ankylosing spondylitis; BMI, body mass index.

${ }^{a} p$ value calculated from regression models estimated using generalised estimating equations (GEEs) to account for the matched nature of the data.

${ }^{b} p$ value calculated from Fisher's exact test, because of zero events in either group in which GEE models do not converge.

0.500). After matching the pregnancies with the number of foetuses, the proportion of LBW infants was similar in women with AS and control subjects ( $p>0.999)$, suggesting that a higher frequency of twin pregnancies could largely explain the higher frequency of LBW infants among AS deliveries. The proportion of SGA infants was also comparable between the two groups $(p=$ o.723). Moreover, there were no statistically significant differences in the rate of other adverse foetal outcomes, such as FGR, congenital malformations, and foetal loss. Regarding major congenital malformations, one infant (3.7\%) of mother with AS was born with congenital heart disease, and two infants (1.9\%) of mother without AS had hydronephrosis and congenital heart disease. The proportion of neonates with low Apgar score was similar in both groups. There was no gender difference between the groups.

The indications of CS included previous CS, breech position, failure to progress and induction failure, placenta previa, and foetal distress, which were comparable between the two groups. Moreover, maternal factors including older age and severe obesity were also similar for the two groups (Table 5). CS due to failure to progress during TOL was performed in one woman with AS (8.3\%) and two women (9.1\%) in the control group ( $p>$ 0.999). Interestingly, the severity of sacroiliitis in patients with AS did not show any association with CS ( $p=$ o.342) (Supplementary Table 3).
In sensitivity analyses, limiting the analysis to first delivery in each mother in both cohorts (Supplementary Tables 4 and 5), women with AS still showed a higher risk of CS than those without AS in the population-based cohort (adjusted OR, 1.75; 95\% CI, 1.50 to 2.04). Also, in the hospital-based cohort, women with AS had a higher frequency of CS compared to the controls $(p=0.047)$, but smaller sample size decreased statistical power.

\section{DISCUSSION}

In this study, women with AS showed higher risk for CS than those without AS, but other maternal and foetal outcomes were comparable, including LBW, after adjusting for the number of foetuses.

The results of the present study are in line with the aforementioned studies of AS and pregnancy. The previous retrospective case-control study with 20 pregnant women with AS demonstrated that pregnancy outcome of patients with AS was not different from that of healthy control subjects, except for older maternal age and higher rate of female foetuses in women with AS [17]. In addition, in the retrospective study involving 12 pregnant women with AS, pregnancy outcome was not significantly affected by the disease [18]. Similarly, a retrospective study including a cohort of 939 patients from the AS International Federation Societies in USA, 
Canada and Europe showed favourable pregnancy and neonatal outcomes in women with AS [19]. However, a recent nationwide population-based case-control study in Sweden was the largest population-based study referring to AS and pregnancy outcome. In that study, women with AS showed higher occurrence of CS (both elective and emergency), preterm delivery and SGA than women without AS [7]. In the present study, the rate of CS was higher in women with AS than in those without AS, but other pregnancy complications were similar between the two groups in both the population- and hospital-based cohorts.

In Korea, the rate of CS was $43 \%$ in 1999 and has remained more than $36 \%$ in the most recent decade $[20,21]$. In 2015 , the CS rate in Korea was $38 \%$, the fourth highest rate among countries in the Organization for Economic Cooperation and Development [22]. In this population-based cohort, the CS rate was 50.8\% in women with AS, which was significantly higher than in matched control subjects and for healthy women in Korea. In a previous study, higher maternal age, socio-economic status and maternal obesity were associated with the increasing rate of CS in Korea [21]. In our population-based cohort, deliveries showed older age among women with AS than without AS; thus, the rate of CS was compared after age matching, but the rate of CS was still higher in women with AS than without AS. Furthermore, in the hospital-based cohort, maternal age and obesity, which are widely known risk factors for CS, were comparable between women with AS and controls. A previous retrospective study revealed high rates of CS in women with AS, attributed to the disease itself in $58 \%$ of the cases [19]. That could be explained by the severity of AS and the tendency for elective CS in a woman with inflammatory joint disease [23]. According to the hospital-based cohort, there was no difference in the indication of CS between AS and the control groups. Furthermore, the rate of emergency CS was similar in both groups, despite higher rate of elective CS in women with AS. The rate of CS owing to failure to progress during TOL was also comparable between women with AS and the controls. In addition, the severity of sacroiliitis, which was assessed by radiographic grading of the sacroiliac joint, did not show any association with CS (Supplementary Table 3). Thus, it is suggested that women with AS tend to undergo CS due to other factors such as concern about AS rather than indication for CS.

In the hospital-based cohort, the frequency of LBW infants was higher among AS deliveries than among control deliveries; however, this seemed to be an artifact of higher frequency of twin pregnancies among women with AS. Interestingly, the proportion of twin pregnancy was higher in women with AS than in control subjects, despite comparable rates of in vitro fertilisation. However, based on HIRA data, delivery in twin pregnancy was not different in patients with AS and the general population. This may be due to the special characteristics of the hospital where higher risk pregnancies, including multiple pregnancies, are managed.

To the best of our knowledge, this is the first population-based study to analyse pregnancy outcomes in Asian women with AS. However, there are some limitations. In the population-based data, we included delivery cases in women with AS; thus, the cases of spontaneous abortions and induced abortions were not included. Secondly, the reason for CS and confounding factors that might affect delivery method, including socio-economic status and maternal obesity, were not assessable though the HIRA database. Further, foetal outcomes, including stillbirth, could not be evaluated in the population-based data because maternal claim information was not linked to foetal information. Thirdly, limitation remains the validity of the diagnoses of pregnancy complications in HIRA database. However, procedure code of delivery was considered more accurate in NHI payment system. This limitation may be compensated by the data of hospital-based cohort; however, all the deliveries in our study were performed in a single centre, and only 27 AS pregnancies were analysed. Furthermore, as Seoul National University Hospital is a tertiary referral centre, there is a high possibility that the study involves high-risk pregnancies. This is positively reflected by a higher frequency of twin pregnancies included in our study compared to that of the general population [24]. Moreover, information on radiographic grading of sacroiliitis was not available in some patients, and women with severe sacroiliitis with total ankyloses were not included in our study.

In conclusion, although deliveries among women with AS are more often performed with CS, other obstetric and perinatal outcomes are not different from those of non-AS deliveries. 


\section{KEY MESSAGE}

1. Women with ankylosing spondylitis (AS) showed higher risk for Caesarean section (CS) than those without AS, but other maternal and foetal outcomes were comparable based on population-based and hospital-based cohort in Korea.

2. Pregnancy outcome is favorable in women with AS except for the higher rate of CS; this result makes pregnancy or delivery more promising for women with AS.

\section{Conflict of interest}

No potential conflict of interest relevant to this article was reported.

\section{Acknowledgments}

We thank the Korean Health Insurance Review and Assessment Service and the National Health Insurance Service for providing the insurance claims data.

This research was supported partly by a grant of the Asan Institute for Life Sciences (grant number 2017-655) and the Korea Health Technology R\&D Project through the Korea Health Industry Development Institute (KHIDI), funded by the Ministry of Health and Welfare, Republic of Korea (grant number: $\mathrm{HC}_{7} \mathrm{CoO}_{9}$ ).

\section{REFERENCES}

1. Exarchou S, Lindstrom U, Askling J, et al. The prevalence of clinically diagnosed ankylosing spondylitis and its clinical manifestations: a nationwide register study. Arthritis Res Ther 2015;17:118.

2. Dean LE, Jones GT, MacDonald AG, Downham C, Sturrock RD, Macfarlane GJ. Global prevalence of ankylosing spondylitis. Rheumatology (Oxford) 2014;33:650-657.

3. West HF. Aetiology of ankylosing spondylitis. Ann Rheum Dis 1949;8:143-148.

4. Gran JT, Husby G. The epidemiology of ankylosing spondylitis. Semin Arthritis Rheum 1993;22:319-334.

5. Ostensen M, Fuhrer L, Mathieu R, Seitz M, Villiger PM. A prospective study of pregnant patients with rheumatoid arthritis and ankylosing spondylitis using validated clinical instruments. Ann Rheum Dis 2004;63:1212-1217.
6. Ostensen M, Husby G. Ankylosing spondylitis and pregnancy. Rheum Dis Clin North Am 1989;15:241-254.

7. Jakobsson GL, Stephansson O, Askling J, Jacobsson LT. Pregnancy outcomes in patients with ankylosing spondylitis: a nationwide register study. Ann Rheum Dis 2016;75:1838-1842.

8. Nystrom MJ, Caughey AB, Lyell DJ, Druzin ML, El-Sayed YY. Perinatal outcomes among Asian-white interracial couples. Am J Obstet Gynecol 2008;199:385.

9. Ruff C, Niskanen M, Junno JA, Jamison P. Body mass prediction from stature and bi-iliac breadth in two high latitude populations, with application to earlier higher latitude humans. J Hum Evol 2005;48:381-392.

10. Ikoma E, Kanda S, Nakata S, Wada Y, Yamazaki K. Quantitative genetic analysis of bi-iliac breadth. Am J Phys Anthropol 1988;77:295-301.

11. Kim JA, Yoon S, Kim LY, Kim DS. Towards actualizing the value potential of Korea Health Insurance Review and Assessment (HIRA) data as a resource for health research: strengths, limitations, applications, and strategies for optimal use of HIRA data. J Korean Med Sci 2017;32:718-728.

12. van der Linden S, Valkenburg HA, Cats A. Evaluation of diagnostic criteria for ankylosing spondylitis. A proposal for modification of the New York criteria. Arthritis Rheum 1984;27:361-368.

13. Eiland E, Nzerue C, Faulkner M. Preeclampsia 2012. J Pregnancy. 2012;2012:586578.

14. Marsal K, Persson PH, Larsen T, Lilja H, Selbing A, Sultan B. Intrauterine growth curves based on ultrasonically estimated foetal weights. Acta Paediatr 1996;85:843-848.

15. Lee JK, Jang HL, Kang BH, et al. Percentile distributions of birth weight according to gestational ages in Korea (2010-2012). J Korean Med Sci 2016;31:939-949.

16. American Academy of Pediatrics Committee on Fetus and Newborn; American College of Obstetricians and Gynecologists Committee on Obstetric Practice. The Apgar score. Pediatrics 2015;136:819-822.

17. Timur H, Tokmak A, Turkmen GG, Ali Inal H, Uygur D, Danısman N. Pregnancy outcome in patients with ankylosing spondylitis. J Matern Fetal Neonatal Med 2016;29:2470-2474.

18. Zhou Q, Bian XM, Liu JT. Management of pregnancy with ankylosing spondylitis. Chin Med Sci J 2012;27:46-49.

19. Ostensen M, Ostensen H. Ankylosing spondylitis: the female aspect. J Rheumatol 1998;25:120-124.

20. Torloni MR. The increasing trend in caesarean section 
rates: global, regional and national estimates: 1990-2014. PLoS One 2016;11:e0148343.

21. Chung SH, Seol HJ, Choi YS, Oh SY, Kim A, Bae CW. Changes in the cesarean section rate in Korea (1982-2012) and a review of the associated factors. J Korean Med Sci 2014;29:1341-1352.

22. OECD. Health at a Glance 2017. Paris (FR): OECD Publishing, 2017.
23. Dunkin MA. Rheumatoid arthritis and pregnancy [Internet]. Atlanta (GA): Arthritis Foundation, 2019 [cited 2019 Sep 3]. Available from: https://www.arthritis.org/living-with-arthritis/life-stages/pregnancy-family/pregnancy-and-rheumatoid-arthritis.php.

24. Hamilton BE, Martin JA, Osterman MJ, Curtin SC, Matthews TJ. Births: final data for 2014. Natl Vital Stat Rep 2015;64:1-64. 
Park EH, et al. Pragnancy outcomes in ankylosing spndylitis

Supplementary Table 1. ICD-10 codes and HIRA procedure code for delivery used in the population-based cohort study

\begin{tabular}{|c|c|}
\hline & Code \\
\hline \multicolumn{2}{|l|}{ Comorbidity (ICD-10) } \\
\hline Hypertension & I10 \\
\hline Diabetes mellitus & E10, E11, E12, E13, E14 \\
\hline Uveitis & $\mathrm{H}_{2} \mathrm{O}, \mathrm{H}_{2} \mathrm{OO}, \mathrm{H}_{2} \mathrm{O} 1, \mathrm{H}_{2} \mathrm{O} 2, \mathrm{H}_{2} \mathrm{O} 8, \mathrm{H}_{2} \mathrm{O} 9, \mathrm{H}_{22}$ \\
\hline Inflammatory bowel disease & $\begin{array}{l}\mathrm{K}_{50}, \mathrm{~K}_{500}, \mathrm{~K}_{501}, \mathrm{~K}_{508}, \mathrm{~K}_{509}, \mathrm{~K}_{51}, \mathrm{~K}_{511}, \mathrm{~K}_{512}, \mathrm{~K}_{513}, \mathrm{~K}_{514}, \mathrm{~K}_{515}, \mathrm{~K}_{518}, \mathrm{~K}_{519} \text {, } \\
\mathrm{K}_{528}, \mathrm{~K}_{529}, \mathrm{Mo}_{4}, \mathrm{M}_{75}\end{array}$ \\
\hline Psoriasis & 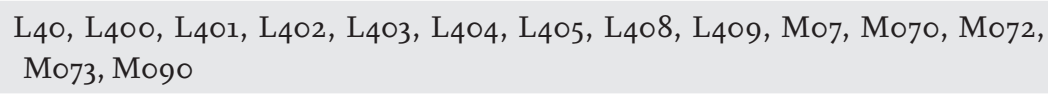 \\
\hline \multicolumn{2}{|l|}{ Pregnancy complication (ICD-10) } \\
\hline Preeclampsia & $\mathrm{O}_{140}, \mathrm{O}_{141}, \mathrm{O}_{149}$ \\
\hline Preterm delivery & $\mathrm{O} 601,0603$ \\
\hline Placental abruption & $\mathrm{O}_{45}$ \\
\hline Other obstetric trauma & $\mathrm{O}_{71}$ \\
\hline Maternal distress during labour and delivery & $\mathrm{O}_{750}$ \\
\hline \multicolumn{2}{|l|}{ Delivery (HIRA procedure code) } \\
\hline Vaginal delivery & $\begin{array}{l}\mathrm{R}_{3131}, \mathrm{R}_{3133}, \mathrm{R}_{3136}, \mathrm{R}_{3138}, \mathrm{R}_{3141}, \mathrm{R}_{3143}, \mathrm{R}_{3146}, \mathrm{R}_{3148}, \mathrm{R}_{4351}, \mathrm{R}_{4353}, \mathrm{R}_{4356} \\
\mathrm{R}_{4358}, \mathrm{R}_{4361}, \mathrm{R}_{4362}, \mathrm{R}_{4380}\end{array}$ \\
\hline Caesarean section & $\begin{array}{l}\mathrm{R}_{4507}, \mathrm{R}_{4508}, \mathrm{R}_{4509}, \mathrm{R}_{4510}, \mathrm{R}_{4514}, \mathrm{R}_{4516}, \mathrm{R}_{4517}, \mathrm{R}_{4518}, \mathrm{R}_{4519}, \mathrm{R}_{4520}, \mathrm{R}_{5001}, \\
\mathrm{R}_{5002}\end{array}$ \\
\hline Twin pregnancy & $\mathrm{R}_{3133}, \mathrm{R}_{313} 8, \mathrm{R}_{3143}, \mathrm{R}_{3148}, \mathrm{R}_{4353}, \mathrm{R}_{4358}, \mathrm{R}_{4516}, \mathrm{R}_{4519}, \mathrm{R}_{4520}, \mathrm{R}_{5001}, \mathrm{R}_{5002}$ \\
\hline Multiparous delivery & $\begin{array}{l}\mathrm{R}_{3136}, \mathrm{R}_{313} 8, \mathrm{R}_{3146}, \mathrm{R}_{3148}, \mathrm{R}_{4356}, \mathrm{R}_{435} 8, \mathrm{R}_{4362}, \mathrm{R}_{4380}, \mathrm{R}_{4508}, \mathrm{R}_{4510}, \mathrm{R}_{4514} \\
\mathrm{R}_{4516}, \mathrm{R}_{4518}, \mathrm{R}_{4520}, \mathrm{R}_{5002}\end{array}$ \\
\hline
\end{tabular}

ICD-10, International Classification of Disease and Related Health Problems, 1oth revision; HIRA, Health Insurance Review and Assessment Service. 
Supplementary Table 2. Baseline characteristics of women with AS and controls: hospital-based cohort

\begin{tabular}{|c|c|c|c|}
\hline Characteristic & Pregnancies with AS $(\mathrm{n}=27)$ & Pregnancies without AS $(\mathrm{n}=108)$ & $p$ value $^{\mathrm{a}}$ \\
\hline Maternal age, yr & $32.3 \pm 3.2$ & $32.2 \pm 3.1$ & 0.856 \\
\hline Prepregnancy BMI, kg/m² & & & $0.648^{b}$ \\
\hline Underweight, $<18.5$ & $7(25.9)$ & $18(16.7)$ & \\
\hline Normal weight, $18.5-24.9$ & $18(66.7)$ & $79(73.1)$ & \\
\hline Overweight, $25-29.9$ & $2(7.4)$ & $9(8.3)$ & \\
\hline Obese, $\geq 30$ & 0 & $2(1.9)$ & \\
\hline Parity & & & 0.853 \\
\hline 0 & $16(59 \cdot 3)$ & $67(62.0)$ & \\
\hline 1 & $9(33.3)$ & $31(28.7)$ & \\
\hline 2 or more & $2(7.4)$ & $10(9 \cdot 3)$ & \\
\hline Previous preterm delivery & $2(7 \cdot 4)$ & $4(3.7)$ & 0.487 \\
\hline Previous delivery method & & & 0.538 \\
\hline No previous delivery & $15(55 \cdot 6)$ & $64(59 \cdot 3)$ & \\
\hline Vaginal delivery & $8(29.6)$ & $37(34 \cdot 3)$ & \\
\hline Cesarean section & $4(14.8)$ & $7(6.5)$ & \\
\hline \multicolumn{4}{|l|}{ Comorbidities } \\
\hline Hypertension/PIH & $1(3.7)$ & $7(6.5)$ & 0.588 \\
\hline GDM & $1(3.7)$ & $8(7 \cdot 4)$ & 0.498 \\
\hline HBV carrier & $2(7.4)$ & $3(2.8)$ & 0.360 \\
\hline Valvular heart disease & 0 & $3(2.8)$ & $>0.999^{b}$ \\
\hline Hyperthyroidism & 0 & $2(1.9)$ & $>0.999^{b}$ \\
\hline Hypothyroidism & $1(3.7)$ & $5(4 \cdot 6)$ & 0.827 \\
\hline Education level & & & 0.788 \\
\hline University & $24(88.9)$ & $94(87.0)$ & \\
\hline High school & $3(11.1)$ & $14(13.0)$ & \\
\hline Smoking & 0 & o & - \\
\hline \multicolumn{4}{|l|}{ Laboratory tests } \\
\hline WBC, $\mathrm{mm}^{3}$ & $8,639 \cdot 6 \pm 2,168.6$ & $9,844 \cdot 3 \pm 2,790.0$ & 0.010 \\
\hline Hemoglobin, g/dL & $11.8 \pm 1.4$ & $11.9 \pm 1.3$ & 0.617 \\
\hline Platelet, $\mathrm{mm}^{3}$ & $233.8 \pm 48.2$ & $212.4 \pm 46.4$ & 0.142 \\
\hline hs-CRP, mg/L & $0.7 \pm 0.8$ & $0.8 \pm 1.6$ & 0.351 \\
\hline $\mathrm{ESR}, \mathrm{mm} / \mathrm{hr}$ & $44.1 \pm 27.6$ & $29.0 \pm 0.0$ & 0.482 \\
\hline HLA-B27 positivity ${ }^{\mathrm{c}}$ & $18(85.7)$ & ND & \\
\hline AS duration, $\mathrm{yr}^{\mathrm{c}}$ & $4.4 \pm 2.7$ & ND & \\
\hline \multicolumn{4}{|c|}{ Medication use prior to pregnancy ${ }^{c}$} \\
\hline NSAIDs & $21(100.0)$ & ND & - \\
\hline Corticosteroid & $6(28.6)$ & ND & \\
\hline Sulfasalazine & $10(47.6)$ & ND & \\
\hline Biologics & $6(28.6)$ & $\mathrm{ND}$ & \\
\hline Azathioprine & $1(4.8)$ & ND & \\
\hline Opioid & o & $\mathrm{ND}$ & \\
\hline
\end{tabular}

Values are presented as mean $\pm \mathrm{SD}$ or number (\%).

AS, ankylosing spondylitis; BMI, body mass index; PIH, pregnancy induced hypertension; GDM, gestational diabetes mellitus; HBV, hepatitis B virus; WBC, white blood cell; hs-CRP, high-sensitivity C-reactive protein; ND, not done; ESR, erythrocyte sedimentation rate; NSAID, nonsteroidal anti-inflammatory drug.

a $p$ value: calculated from regression models estimated using generalised estimating equations (GEEs) to account for the matched nature of the data.

${ }^{b} p$ value: calculated from Fisher's exact test or chi-square test because of zero events in either group in which GEE models do not converge.

${ }^{c}$ Pregnancies with AS with medical records of the rheumatologic clinic $(n=21)$. 
Park EH, et al. Pragnancy outcomes in ankylosing spndylitis

Supplementary Table 3. Caesarean section rate according to grading of sacroiliitis in patients with AS: hospital-based cohort

\begin{tabular}{|c|c|c|c|}
\hline Grading of sacroiliitis & Number & Caesarean section, n (\%) & $p$ value $^{\mathrm{a}}$ \\
\hline Bilateral grade 2 & 12 & $4(33 \cdot 3)$ & 0.053 \\
\hline Unilateral grade 3 & 4 & $4(100.0)$ & \\
\hline Bilateral grade 3 & 6 & $2(33 \cdot 3)$ & \\
\hline Total ankyloses & 0 & - & \\
\hline
\end{tabular}

AS, ankylosing spondylitis.

${ }^{a} p$ value: calculated from chi-square test, $p$ value $=0.342$ tested for trend. 
Supplementary Table 4. Pregnancy outcomes in women with AS and control: Korean HIRA claims database (primipara)

\begin{tabular}{|c|c|c|c|c|c|c|}
\hline Outcome & With AS $(n=749)$ & Without AS $(n=6,403)$ & OR & $95 \% \mathrm{CI}$ & Adjusted OR & $95 \% \mathrm{CI}$ \\
\hline No complication (ref) & $327(43.7)$ & $3,601(56.2)$ & 1.00 & & 1.00 & \\
\hline Overall complication & $422(56.3)$ & $2,802(43.8)$ & 1.66 & $1.42-1.93$ & $1.67^{\mathrm{a}}$ & $1.43-1.95$ \\
\hline Caesarean section & $404(53 \cdot 9)$ & $2,576(40.2)$ & 1.74 & $1.49-2.03$ & $1.75^{\mathrm{a}}$ & $1.50-2.04$ \\
\hline Preeclampsia & $13(1.7)$ & $64(1.0)$ & 1.75 & $0.96-3.19$ & $1.78^{\mathrm{b}}$ & $0.95-3.33$ \\
\hline Preterm delivery & $8(1.1)$ & $81(1.3)$ & 0.84 & $0.41-1.75$ & & \\
\hline Placental abruption & o & $7(0.1)$ & $\mathrm{NE}$ & & & \\
\hline Other obstetric trauma & $7(0.9)$ & $146(2.3)$ & 0.40 & $0.19-0.87$ & & \\
\hline $\begin{array}{l}\text { Maternal distress } \\
\text { during labour and delivery }\end{array}$ & o & $3(0.05)$ & $\mathrm{NE}$ & & & \\
\hline Twin pregnancy & $4(0.5)$ & $14(0.2)$ & 2.45 & $0.80-7.46$ & & \\
\hline
\end{tabular}

Values are presented as number (\%).

AS, ankylosing spondylitis; HIRA, Health Insurance Review and Assessment Service; OR, odds ratio; CI, confidence interval; NE, not estimated.

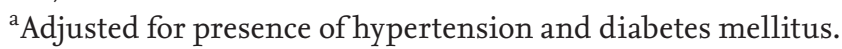

${ }^{\mathrm{b}}$ Adjusted for presence of hypertension. OR of maternal complications compared between two groups using a generalized linear model with binomial distribution. 
Supplementary Table 5. Maternal and foetal outcomes in first delivery of women with AS and controls: hospital-based cohort (primipara)

\begin{tabular}{|c|c|c|c|}
\hline Outcome & With AS $(n=21)$ & Without AS $(\mathrm{n}=108)$ & $p$ value $^{a}$ \\
\hline Caesarean section & $9(42.9)$ & $22(20.4)$ & 0.047 \\
\hline Elective & $6(28.6)$ & $16(14.8)$ & 0.061 \\
\hline Emergency & $3(14 \cdot 3)$ & $6(5.6)$ & 0.061 \\
\hline CS among trial of labor & $1 / 13(7.7)$ & $4 / 90(4 \cdot 4)$ & 0.498 \\
\hline Preeclampsia & O & $4(3.7)$ & $>0.999^{b}$ \\
\hline Preterm delivery & $3(14 \cdot 3)$ & $6(5.6)$ & 0.163 \\
\hline Maternal death & $\mathrm{O}$ & $\mathrm{O}$ & - \\
\hline Transfusion & 0 & $2(1.9)$ & $>0.999^{b}$ \\
\hline Gestation, wk & $38.8 \pm 1.5$ & $39.0 \pm 1.8$ & 0.730 \\
\hline Hospital stay, day & $4.1 \pm 2.9$ & $5.1 \pm 7.9$ & 0.283 \\
\hline Low birth weight & $5(23.8)$ & $9(8.3)$ & 0.052 \\
\hline Small-for-gestational-age & $3(11.1)$ & $10(9 \cdot 3)$ & 0.723 \\
\hline Neonatal weight, g & $2,922.8 \pm 527.0$ & $3,063.6 \pm 507.5$ & 0.213 \\
\hline Twin pregnancy & $4(19.0)$ & $8(7 \cdot 4)$ & 0.107 \\
\hline In vitro fertilisation & $3(14 \cdot 3)$ & $11(10.2)$ & 0.700 \\
\hline Fetal growth restriction & $2(9 \cdot 5)$ & $5(4 \cdot 6)$ & 0.319 \\
\hline Congenital malformation & $1(4.8)$ & $1(0.9)$ & 0.300 \\
\hline Fetal loss & O & O & - \\
\hline 1 min Apgar Score $<4^{c}$ & $1(4 \cdot 0)$ & $2(1.7)$ & 0.446 \\
\hline 5 min Apgar Score $<7^{c}$ & $1(4.0)$ & $4(3 \cdot 5)$ & $>0.999$ \\
\hline Sex of child, female ${ }^{c}$ & $13(52.0)$ & $64(55 \cdot 2)$ & 0.827 \\
\hline
\end{tabular}

Values are presented as number (\%) or mean $\pm \mathrm{SD}$.

AS, ankylosing spondylitis; CS, Caesarean section.

${ }^{a} p$ value calculated from regression models estimated using generalised estimating equations (GEEs) to account for the matched nature of the data.

${ }^{b}$ p value calculated from Fisher exact test, because of zero events in either group in which GEE models do not converge.

${ }^{\mathrm{c} A n a l y s e d}$ by neonates and information of twins, pregnancies with $\mathrm{AS}(\mathrm{n}=25)$ and pregnancies without $\mathrm{AS}(\mathrm{n}=116)$. 


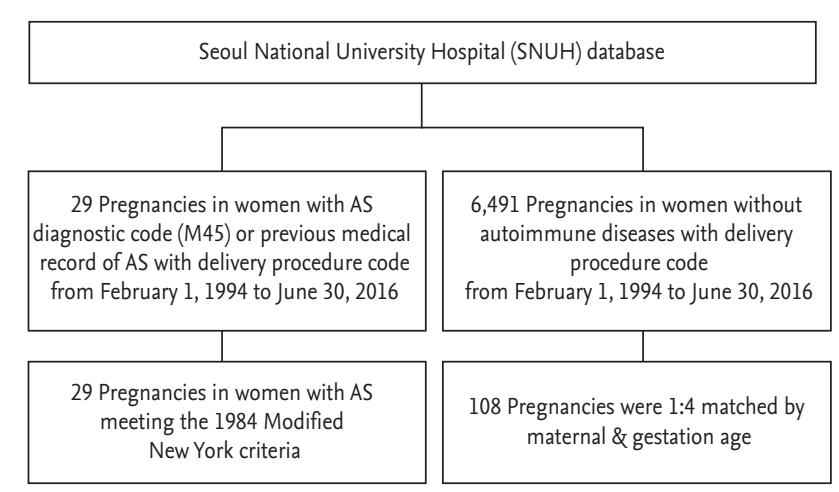

Supplementary Figure 1. Selection of study participants from the Seoul National University Hospital and Assessment Service database. AS, ankylosing spondylitis. 